\title{
An Account of Ethics, Deontological Theory and its Applications in Understanding Ethical Impermissibility of Euthanasia
}

\section{Gupta C and Sachdev KN*}

Department of Humanities and Social Sciences, Birla Institute of Technology and Science, India

*Corresponding author: Kumar Neeraj Sachdev, Associate Professor of Philosophy, Department of Humanities and Social Sciences, Birla Institute of Technology and Science (BITS), Pilani Campus, Pilani-333031, Rajasthan, India, Email: kns@pilani.bits-pilani.ac.in

\section{Conceptual Paper}

Volume 3 Issue 2

Received Date: May 25, 2020

Published Date: June 09, 2020

DOI: $10.23880 /$ abca-16000122

\section{Abstract}

We present in the paper a brief account of ethics and its theoretical frameworks, focusing in particular on deontological theory. We extend the account of ethics to applied ethics in order to analyze various applications of deontological theory for enhancing the understanding of ethical impermissibility of euthanasia.

\section{Ethics and its Theories}

Ethics is a branch of Philosophy, which is concerned with the questions such as how one ought to live, and what constitutes good and right conduct for human beings. It is considered as one's critical ability to think about the nature of human values and what is "right" or "wrong" in the domain of actions [1]; an ethical theory provides decisive reasons for the rightness and wrongness of an action or rule. An ethical theory can be prescriptive because it guides our actions. It also tells us what sorts of rules are rationally defensible or not. An ethical theory can be taken as universal because it applies to all human beings who have similar moral situations that are genuine and relevant. An ethical theory is taken as practical as well because it applies to human beings living in the real and empirical world. There are three major areas of Ethics which are as follows:

\section{Normative Ethics}

Normative ethicists investigate the idea of good human life on the one hand and the standards of good or bad and right or wrong to formulate fundamental moral principles applicable across the spectrum of human actions on the other. They try to know what makes human life worth living or what makes a human action good or bad and right or wrong. It is a practical way of determining moral course of action for the welfare of an individual human being. There are many ethical theories of normative ethics out of which three well-known theories are as follows:

Utilitarian Theory: Utilitarian Theory is also known as consequentialist ethics. It depends upon the ethical analysis of consequences of an action. It covers two aspects such as good and right. Good aspect specifies those goals which are morally worthy of pursuit. For example individual wellbeing is regarded as the relevant goal of pursuit. Right aspect specifies what is to be done in regard to the good. It depends upon the principle of maximization. It means that the good should be maximized. An action is taken as morally right only when it contributes to the maximum achievement of the good. The principle of greatest happiness for maximum number of people is regarded as the good specified in Utilitarian theory. Jeremy Bentham is regarded as one of the prominent philosophers who provide an account of utilitarianism. Happiness is regarded as a hedonistic notion which talks about relative worth of pleasures. Hedonistic calculus' main aim is to calculate the sum total of pleasure and pain which is born out from the consequence of a specific action.

According to Bentham, achieving pleasure and avoiding pain is important in human nature. John Stuart Mill presented a systematic account of utilitarianism and in his account improvised upon Bentham's idea of quantitative approach to happiness. Mill wants to show that utilitarianism is 
essentially consistent with commonsense morality Norman $\mathrm{R}$, et al. [2]. He talked about higher and lower pleasures. According to Mill, both quality and quantity of pleasures needs to be considered. Intellectuality and creativity are regarded as examples of higher pleasures whereas eating and drinking are regarded as examples of lower pleasures. There are two types of Utilitarianism namely act and rule.

$>$ Act-utilitarianism deals with the principle of maximization of overall happiness produced by an action.

$>$ Act-utilitarianism stipulates morally right act as one which produces overall happiness as much as possible in the particular situation.

The act which produces overall general happiness is considered morally right. Bentham quantifies the amount of happiness gained or lost. According to rule-utilitarianism, the right act conforms to the rule which when followed produces overall happiness as much as possible. It generates rules and actions will follow such rules that are based upon the idea of promotion of general happiness. For example, people should keep their promises will come under the notion of ruleutilitarianism.

Deontological Theory: Deontological theory is also known as Kantian Ethics because it was first proposed and developed by Immanuel Kant. This theory is based upon duty ethics. According to Kant, a person should act in a morally right way. The consequence of actions does not make human action right or wrong because the motive of the person carries out the moral explanation of whole action. He said that a person acts in a certain way because he or she realizes that it is his duty to respect the moral law. Highest goodness is found within oneself only, which can be proved through one's morally justified motive to act. He talked about categorical imperative. A categorical imperative is regarded as an absolute and unconditional command or requirement that must be followed or obeyed in all situations and is an end in itself. The categorical imperative sets forth the rules of a good will Kant I, et al. [3]. The categorical imperative has three important formulations which are as follows:

Act in such a way so that it will become a universal law of nature and is applicable on each and every individual [4]. Kant said that if I cannot will the maxim of my action to be a universal law, then it must be wrong Singer P, et al. [5]. In this first formulation, Kant divides duties into two parts such as duties towards us and duties towards others. For example, it is a duty of a human being to not to kill himself as well as others. There are two types of duties such as perfect and imperfect duties. Perfect duties tell us that never act by those maxims which are wrong and are not able to be applicable on all. For example, we cannot say that you steal something because this act is wrong and cannot be applied universally.
Imperfect duties are regarded as those duties which will be never completed because it is depended upon subjective desires and preferences of a human being. The cultivation of one's own talents and capabilities will be regarded as an example of imperfect duty.

The dignity of human beings must be maintained while performing an act. It has been said in the second formulation that act in such a way so that humans should not be treated as means for themselves or for others because humanity should be treated only as an end in itself. 'Never treat anyone as a means to satisfy your own end or purpose. For example if we want a person to do a specific action then we should not fool that person. Autonomy of oneself and others should be respected because it includes rational free will or desires. The third formulation combines both first and second formulations. It has been said that a human being must act rationally in such a way so that he becomes a legislating member of universal kingdom of ends. Every rational will becomes universal legislative will. This formulation does not curtail individual and others' freedom and prescribes that one ought to act by those principles or maxims that are related to possible kingdom of ends.

Virtue Theory: Virtue theory focuses on the ways of actions or on habits of a person. It examines moral status of persons which include character. It describes and analyzes virtues in presenting an overall picture of the character of an individual. It focuses on the notion of good character and if a person has good character then he or she is treated as a good person because he or she performs his function as a rational human being. Human beings must develop their common attribute that is rationality, which is possessed by all. Rationality means an ability to use one's reason to arrive at judgments for various purposes in one's life. Aristotle refers to eudaimonia, which means that human beings are capable of pursuing highest form of life i.e. good life. Good life leads to happiness and happiness is considered to be an activity of the rational part of the soul in accordance with virtue. Basically, happiness characterizes typical function of a human being for its own well-being in the world. And for this, Aristotle says, we should act virtuously in order to live good human lives. Honesty and generosity are two examples of virtues. These and other virtues define a person's character.

\section{Applied Ethics}

Ethics is a practical science. But still in second half of twentieth century onward many thinkers have started applying ethical rules and principles based upon ethical theories to understand the moral dimensions of particular human actions in various social and professional domains. With the result, we get to see varied practical applications of Ethics in understanding moral perspectives of real life issues 
such as euthanasia, abortion, suicide and so on. We shall focus upon a deontological perspective of Euthanasia in the remaining part of paper.

\section{Euthanasia}

Euthanasia is defined as mercy killing or good death. According to Dictionary, 'euthanasia' refers to 'a gentle and easy death', but it is now used to refer to the killing of those who are incurably ill and in great pain or distress, in order to spare them further suffering or distress Singer P, et al. [5]. It has been formally said that person A ends the life of person $B$ for the sake of person $B$. This is done to bring about a good death of person $B$ for the sake of B. It is important to stress on the fact that the motive behind euthanasia is the ultimate benefit that is welfare of the patient Budic M, et al. [6]. If we turn to the roots of Western tradition, we find that in Greek and Roman times such practices as infanticide, suicide and euthanasia were widely accepted [7].

Euthanasia involves a deliberate action of taking away an individual's life typically because the individual concerned unbearably suffers from an incurable disease. It has been said that it is the duty of a human being not to deliberately take away his or other human being's life because life has sanctity. According to Kant, man has no power to dispose of his or her own life. It is the duty of an individual to respect his or her own dignity of life. Cholbi informs, "Rational agents are morally obligated to preserve themselves because they possess a kind of incomparable value, which Kant called 'dignity', to destroy a rational agent, even one for the sake of one's own well-being is to fail to honour this dignity" [8].

If we are taking someone life's deliberately then we are treating that person as a means and not as an end in himself. It is possible that I am treating a person as a means to an end and thereby undermining the personhood in him Brassington I, et al. [9]. According to some thinkers, euthanasia should be ethically permissible because of the principles of autonomy and sympathy. A person has freewill to do whatever he wants to do. An argument in favour of euthanasia is given that we should respect the principle of autonomy. But if euthanasia is taken in reference with deontological ethics then duty which is a moral maxim has to be followed and no duty suggests ending one's own or other's life. Further we may note that euthanasia has three forms, which are as follows:

Voluntary Euthanasia: In case of voluntary euthanasia, person B suffering from an incurable illness but in a mental position to freely arrive at a rationally considered judgment, requests his or her doctor (person $\mathrm{A}$ ) to end his or her life. A patient's decision to end his life is primarily controversial because death is seen, generally, as a bad thing [10], and the person $\mathrm{A}$ after consulting his senior professionals and person B's family initiates the procedure to end his life. In such a case lethal injection is given by a doctor (person $A$ ) to his or her patient (person B) to end his life.

Non-Voluntary Euthanasia: In case of non-voluntary euthanasia, person $B$ is not in a rational state of mind to choose between life and death for himself because that person is not a position to know that his disease is incurable and thereby he or she cannot give any consent as such. In this form of euthanasia, person B's consent is unavailable. Person A, typically a doctor, takes the decision to end his life without there being any question of consent of person B. If this form of euthanasia is taken from the deontological perspective then it implies that it is the duty of a doctor not to take the life of any person, whether that person B has given his or her consent or not.

Involuntary euthanasia: In this form of euthanasia, person $\mathrm{B}$ is mentally in a position to give his or her consent but nobody asks him whether he wants to end his life. This form of euthanasia is very rare and it is against the will of the patient (person B). However, it cannot be treated as an act of murder because, theoretically speaking, first, in this form of euthanasia person $A$ ends the life of person $B$ for the sake of $B$ even if person B doesn't get his share of freedom to choose euthanasia; second, person A ends the life of person B for the sake of saving some other person C. It is obvious that in this form of euthanasia person $A$, who happens to end the life of person $B$, never does it for his own selfish gains but for $B$ or $C$ but the fact remains that autonomy of person $B$ is lacking in making a choice for euthanasia.

Active or Passive Euthanasia: It has been further said that these three forms of euthanasia can either be active or passive. In active or positive euthanasia, lethal injection is used to end person B's life by person A (doctor) whereas in passive or negative euthanasia withholding treatment for ending a patient's (person B's) life is used. Doctor (person A) withholds or refrains from providing treatment when it is required if the consent has been given by patient's relative, close friends or family members.

However, it is a duty of the doctor and family members of the patient to try every method to save person B's life although person B may want to end his or her life. If no one is there for the patient then doctor is treated as a friend who can decide in the matter for helping the patient $B$ to come out of his state of mind to opt for euthanasia.

At this stage, we present critical deontological analyses of some arguments that are generally given in favour of euthanasia. 


\section{Autonomy}

It is the autonomy of a person B to end his or her life. We should respect this principle. This argument supports euthanasia. The principle of autonomy should not be misused because it is the duty of each and every person to not to end his or her or others' life. Human Dignity should be maintained because autonomy is the ground of dignity of every rational human being [4].

\section{Mercy for the Patient}

Family members and doctors witness the incurable condition of unbearable suffering of the patient and in an act of mercy decide to end patient's life. There is a possibility that the patient gives his consent or else he may not be in a position to give his consent.

\section{Heavy Expenses of Medical Treatment}

It has been said because person $B$ is in an incurable position and his family is not able to bear medical expenses of person B's treatment that is why person B's life should be ended. This argument is in favour of euthanasia. But against this argument we can say that today's technology is very much advanced and can cure the disease but it takes time. It is the collective duty of a family to treat the patient as an end and not as a means.

\section{Intention or Desire Plays an Important Role}

If person $B$ has a desire to end his or her life then family or doctor (person B) should convince the patient that taking life deliberately will disrespect the value and dignity of human life. It depends upon the family to continue with life-sustaining treatment of a patient or not. If the family continues with the treatment of a patient then it shows the universal aspect of duty of caring that shows that the patient is being treated as an end and not merely as a means whose life can be disposed of like an object in the absence of any instrumental value as such. The family of patient has to ensure also that the doctor is using life sustaining treatment to cure the patient and not just making a fool of patient's family. Intentional killing of a person or letting someone die is regarded as a wrong act because such an act cannot be universalized and opens the way to treat human beings as means and not as ends.

\section{Conclusion}

We have presented a brief account of ethics, theories of ethics focusing in particular on deontological theory and have gone further into applied ethics thereby paving the way for the deontological analysis of euthanasia. Deontological theory as we have noted is based upon the fundamental idea of duty to respect the moral law and that in essence happens to be the basis of rationally establishing the moral permissibility of a human action. Euthanasia happens to be an example of a human action that has invited an extensive debate for long from various perspectives in the area of applied ethics. The reason being euthanasia is all about taking of a human life, which is why it appears to be a moral dilemma of a significant order in individual or collective deliberations.

We have noted that euthanasia works on autonomy of the patient to opt for it and if the situation demands it also involves doctors' and other people's mercy on him to end his unbearable suffering. Whereas it has also been observed in the paper that deontological approach to a human action reminds us about what we ought to do that can be universally applicable and euthanasia as an example of human action can neither be universalized nor sets an example of treating humanity as an end. Rather it ends up treating human beings as means in many instances of euthanasia.

Therefore, the whole discussion in the paper on ethics, ethical theories and eventually deontological analysis of euthanasia leads to an understanding of euthanasia, which brings out the ethical impermissibility of it.

\section{References}

1. Pojman PL, James F (2012) Ethics: Discovering Right and Wrong. USA: Wadsworth: Cengage Learning.

2. Norman R (1998) The Moral Philosophers: An Introduction to Ethics. 2 ${ }^{\text {nd }}$, (Edn.), New York: Oxford University Press, pp: 248.

3. Kant I (1997) Lectures on Ethics. United Kingdom: Cambridge University Press.

4. Kant I (1998) Groundwork of the Metaphysics of Morals. UK: Yale University Press, pp: 224.

5. Singer $P$ (2011) Practical Ethics. $2^{\text {nd }},(E d n)$, USA: Cambridge University Press.

6. Budic M (2017) Suicide, Euthanasia and the Duty to Die: A Kantian Approach to Euthanasia. Philosophy and Society 29(1): 1-152.

7. Singer P (1993) A Companion to Ethics. Willey-Blackwell, pp: 592.

8. Cholbi M (2015) Kant on euthanasia and the duty to die: Clearing the air. Journal of Medical Ethics 41(8): 607610. 


\section{Annals of Bioethics \& Clinical Applications}

9. Brassington I (2006) Killing People: What Kant could have said about Suicide and Euthanasia but did not. J Med Ethics 32(10): 571-574.
10. Nathan R (2015) Is Euthanasia Morally Permissible? Why or Why Not?. Sound Decisions: An Undergraduate Bioethics Journal 1(1): 1-8. 